\title{
Simulating canopy temperature for modelling heat stress in cereals
}

\author{
H. Webber ${ }^{1}$, F. Ewert ${ }^{1}$, B.A. Kimball ${ }^{2}$, S. Siebert ${ }^{1}$, J.W. White ${ }^{2}$, G.W. Wall ${ }^{2}$, M.J. \\ Ottman $^{3}$, D.N.A. Trawally ${ }^{4}$ and T. Gaiser ${ }^{1}$ \\ [1] University of Bonn, Institute of Crop Science and Resource Conservation (INRES), \\ Crop Science Group, Katzenburgweg 5, 53115 Bonn, Germany
}

[2] U.S. Arid-Land Agricultural Research Center, USDA, Agricultural Research Service, 21881 North Cardon Lane, Maricopa, Arizona, 85138, USA

[3] School of Plant Sciences, University of Arizona, Tucson, Arizona 85721, USA

[4] Department of Civil Engineering, College of Engineering, Kwame Nkrumah University of Science and Technology, Kumasi-Ghana

Correspondence to: H. Webber (hwebber@uni-bonn.de), +49(0)228737198 (tel), $+49(0) 228732870$ (fax)

\section{Abstract}

Crop models must be improved to account for the effects of heat stress events on crop yields. To date, most approaches in crop models use air temperature to define heat stress intensity as the cumulative sum of thermal times (TT) above a high temperature threshold during a sensitive period for yield formation. However, observational evidence indicates that crop canopy temperature better explains yield reductions associated with high temperature events than air temperature does. This study presents a canopy level energy balance using Monin-Obukhov Similarity Theory (MOST) with simplifications about the canopy resistance that render it suitable for application in crop models and other models of the plant environment. The model is evaluated for a uniform irrigated wheat canopy in Arizona and rainfed maize in Burkina Faso. No single variable 
regression relationships for key explanatory variables were found that were consistent across the sowing to explain the deviation of canopy temperature from air temperature. Finally, thermal times determined with simulated canopy temperatures were able to reproduce thermal times calculated with observed canopy temperature, whereas those determined with air temperatures were not.

\section{Introduction}

Brief periods of high temperatures occurring around anthesis can severely reduce grain yield in cereals (Ferris et al., 1998; Gourdji et al., 2013; Hawkins et al., 2013; Lobell et al., 2011; 2013; Schlenker and Roberts, 2009). Future climate change is expected to bring more frequent heat stress events, due to both more climate variability (Field et al., 2012) and higher mean temperatures (Hatfield et al., 2011; Seneviratne et al., 2012). This evidence has led to calls to improve the ability of crop growth models to account for such acute heat stress effects because such models are the primary tools used to assess impacts, and adaptation strategies, of climate change on crops (Ewert et al., in press; Rötter et al., 2011; White et al., 2011a). However, few models currently include such heat stress mechanisms such as reductions in grain number or accelerated leaf senescence (for recent exceptions, see Asseng et al., 2011; Deryng et al., 2014; Moriondo et al., 2011) in response to heat stress intensity. One approach to quantify heat stress intensity is with the cumulative sum of thermal times (TT) above a high temperature threshold during a sensitive period for yield formation, which may vary with the processes considered. To date, such efforts have considered variations of air temperature (e.g. daily maximum air temperature) although much evidence suggests that crop canopy temperature explains yield reductions associated with high temperature events better than air temperature (Craufurd et al., 2013; Siebert et al., 2014).

Canopy temperature $\left(T_{c}\right)$, as used in this study, represents the temperature experienced by the uppermost portion of the vegetative canopy of a crop, which can deviate significantly from air temperature depending on the combination of many weather, plant and soil variables and crop management such as irrigation (Durigon and 
de Jong van Lier, 2013; Siebert et al., 2014). Vertical gradients of temperature exist inside the crop canopy (Rattalino Edreira and Otegui, 2012), yet differentiation of average crop canopy temperature from ambient air temperature may be sufficient for large scale applications. For example, at a regional scale irrigation can reduce even ambient daily maximum air temperature by several degrees (Kueppers et al., 2007; Lobell et al., 2008), whereas reduced transpiration resulting from limited soil water and related drought stress can cause crops to be several degrees warmer than the ambient air temperature (Siebert et al., 2014). This deviation of canopy temperature from air temperature is expected to have implications for crop models used in climate impact studies considering heat stress.

Some crop models do consider canopy temperature, such as the rice sterility model of van Oort et al. (2014), SIRIUS (Jamieson et al., 1995; Jamieson et al., 1998), and STICS (Brisson et al., 1998). All employ semi-empirical formulations based on canopy level energy balances, though their assumptions of neutral stability conditions likely render them inappropriate when canopy temperature deviates much from air temperature (Liu et al., 2007), as would be expected with combinations of high water stress (Allen et al., 1998), low wind speeds and high radiative heating. Such deviation can be demonstrated using simple regressions of canopy temperature depression versus any of these variables (e.g. Siebert et al., 2014). Further, the most empirical expressions cannot be expected to be valid outside the regions for which they were developed, and are perhaps not valid for the same region under climate change. More robust and physically defensible formulations of canopy temperature require corrections for boundary layer stability conditions (Monteith and Unsworth, 1990). While some ecosystem models (e.g. Grant et al., 2012), models of the plant physical environment (e.g. Mihailovic and Eitzinger, 2007) and models to control experimental heating of crops (Kimball et al., 2008; Kimball et al., 2015) do consider these physically based estimates of canopy temperature, no examples of their use with crop models are reported in the literature.

In the Monin-Obukhov Similarity Theory (MOST), generalized logarithmic momentum, temperature and water vapour fluxes are calculated as a function of atmospheric stability conditions by applying a stability correction factor (Monin and 
Obukhov, 1954; Webb, 1970). These functions depend on boundary layer stability ( $\mathrm{z} / \mathrm{L})$ where the Monin-Obukhov length $(L)$ specifies the height $(z)$ under which the shear forces dominate relative to buoyant forces. Practically, it determines under which conditions forced convection dominates and only knowledge of standard weather variables and wind speed are needed to determine canopy temperature in a straightforward calculation. On the other hand, when free convection is important and stability correction functions required, analytical solutions are not possible and iterative calculation procedures must be used due to the interdependence of the stability functions and canopy temperature (Liu et al., 2007). As reviewed by Dyer (1974), different formulations of these first order stability correction functions exist, but obtaining reliable gradient measurements to evaluate them, particularly for temperature, is difficult due to the highly fluctuating nature of the atmosphere (Webb, 1970).

The objective of this paper is to present and evaluate a physically based approach to simulate canopy temperature based on Monin-Obukhov Similarity Theory (MOST) that is suitable for application in crop models (for crops with uniform canopy cover) and is robust across locations, crops and climatic conditions. While the approach will be evaluated in a crop model, it should also be relevant and applicable to ecosystem models (e.g. ecosys) and dynamic vegetation models as part of SVAT (soil-vegetation-atmosphere transfer) models (e.g. CLM, the community land model). As part of the effort to evaluate the approach, empirical relationships between the deviation of canopy from air temperature and key variables determining canopy temperature are explored to compare simulated and observed relationships. A third objective is to compare the use of simulated canopy temperature versus air temperature for their ability to reproduce thermal times based on observed crop thermal times.

\section{Methods}

\subsection{Model description}

The hourly canopy temperature model (CanopyT) described below is implemented in the SIMPLACE (Scientific Impact assessment and Modeling PLatform for Advanced Crop and Ecosystem management) modeling framework (Gaiser et al., 2013) together 
with the Lintul5 (Wolf, 2012) crop growth model and an hourly modification of the water balance model, DRUNIR, from the Lintul2 crop growth model (Spitters and Schapendonk, 1990; Van Oijen and Leffelaar, 2008). Lintul5 is used to simulate crop growth and development, whereas DRUNIR is used to simulate crop water demand and uptake. DRUNIR replaces the very similar water balance in LINTUL5 to enable the model to be run successively over many seasons and/or years. The combined model solution is denoted as SIMPLACE<Lintul5, DRUNIR, CanopyT>. The LINTUL models have been evaluated and used in climate change impact assessment studies (e.g. Angulo et al., 2013; van Ittersum et al., 2003), and used in the SIMPLACE modeling framework at field (Gaiser et al., 2013), country and continental scales (Zhao et al., 2015).

Following the derivation presented by Clawson et al. (1989), an expression for canopy temperature, $T_{c}$, can be derived from an energy balance at the crop surface:

$$
R n=L E+G
$$

where $R_{n}$ is the net radiation incident at the crop surface (positive downward), $H$ the sensible heat flux (positive upward), LE the latent energy flux (positive upward) and G the soil heat flux (positive downward).

$R_{n}$ is the sum of net shortwave radiation $\left(R_{n s}\right)$, and net longwave radiation $\left(R_{n 1}\right) \cdot R_{n l}$ is computed as the sum of outgoing longwave radiation from the cropped surface and down-welling longwave radiation from the ambient atmosphere, both determined using the daily procedure in Allen et al. (1998), plus down-welling longwave radiation from the experimental infrared heaters.

Following Monteith and Unsworth (1990), LE is expressed using an analogy to Ohm's Law of electrical resistance as:

$$
L E=\rho c P e c *-e a \gamma r c+r a
$$

where $\rho$ is the density of air, $C_{P}$ the specific heat of air, both evaluated at air temperature, $T_{a}, e_{c}{ }^{*}$ the saturated vapour pressure of air at the crop surface temperature, $T_{c}, e_{a}$ the actual vapour pressure, $\gamma$ is the psychometric constant and $r_{c}$ the canopy surface resistance to vapour transport. $r_{c}$ is largely controlled by stomatal 
conductance, $r_{\mathrm{s}}$, and calculated for the canopy as a function of the actively transpiring leaf area index, $L A l_{\text {active, as }} r_{c}=r_{s} / L A l_{\text {active }}$ (Allen et al., 1998). $r_{a}$ is the bulk aerodynamic resistance to vapour transport, with the common assumption that the aerodynamic resistance to heat and vapour transport are equivalent (Monteith and Unsworth, 1990). Variables used in the model are summarized with units in Table 1.

Table 1. Main variable descriptions, symbols and unit used for computation of canopy temperature in SIMPLACE<Lintul5, DRUNIR, CanopyT>. Dimensionless numbers $\left(\zeta, \zeta_{\mathrm{m}}\right.$, $\left.\zeta_{h}, X\right)$ that are used in equations to condense equations [14] to [21] are not included in this table.

\begin{tabular}{|c|c|c|}
\hline Variable & Description & Units \\
\hline$C_{P}$ & specific heat of air & $\mathrm{J} \mathrm{kg}^{-1}{ }^{\circ} \mathrm{C}^{-1}$ \\
\hline d & zero-displacement height & $\mathrm{m}$ \\
\hline$d_{\text {crop }}$ & zero-displacement height of the crop & $\mathrm{m}$ \\
\hline$d_{R}$ & average zero-displacement height of the crops in surrounding region & $\mathrm{m}$ \\
\hline$d_{w s}$ & zero-displacement height of surface under the weather station & $\mathrm{m}$ \\
\hline $\mathrm{D}$ & characteristic dimension of flat plate with free convection & $\mathrm{m}$ \\
\hline $\mathrm{e}_{\mathrm{a}}$ & actual vapour pressure of air & $\mathrm{kPa}$ \\
\hline$e_{a}^{*}$ & saturated vapour pressure of the air & $\mathrm{kPa}$ \\
\hline$e_{c}^{*}$ & saturated vapour pressure of air at the crop surface temperature & $\mathrm{kPa}$ \\
\hline G & Soil heat flux & $W m^{-2}$ \\
\hline $\mathrm{H}$ & Sensible heat flux & $W m^{-2}$ \\
\hline $\mathrm{H}_{0}$ & Initial estimate of sensible heat flux & $W m^{-2}$ \\
\hline k & von Karmin constant & - \\
\hline $\mathrm{K}_{\mathrm{ws}}$ & crop water stress coefficient & - \\
\hline L & Monin-Obukhov length & - \\
\hline LE & Latent energy flux & $W m^{-2}$ \\
\hline $\mathrm{LAl}_{\text {active }}$ & actively transpiring leaf area index & - \\
\hline $\mathrm{n}$ & parameter to determine $r_{a}$ under free convection & - \\
\hline$r_{a}$ & $\begin{array}{l}\text { bulk canopy resistance to heat and vapour transport (neutral } r_{a} \text { is the } \\
r_{a} \text { calculated assuming neutral stability conditions) }\end{array}$ & $s \mathrm{~m}^{-1}$ \\
\hline$r_{c}$ & canopy surface resistance to vapour transport & $\mathrm{s} \mathrm{m}^{-1}$ \\
\hline
\end{tabular}




\begin{tabular}{|c|c|c|}
\hline$r_{\mathrm{s}}$ & stomatal conductance & $\mathrm{s} \mathrm{m}^{-1}$ \\
\hline $\mathrm{R}_{\mathrm{n}}, \mathrm{R}_{\mathrm{ns}}, \mathrm{R}_{\mathrm{nl}}$ & Net radiation, net shortwave radiation, and net longwave radiation & $W m^{-2}$ \\
\hline Ri & Richardson number & - \\
\hline $\mathrm{T}_{\mathrm{a}}$ & air temperature at reference height & ${ }^{\circ} \mathrm{C}$ \\
\hline $\mathrm{T}_{\mathrm{a}, \mathrm{abs}}$ & absolute air temperature at reference height & $\mathrm{K}$ \\
\hline $\mathrm{T}_{\mathrm{c}}$ & canopy temperature & ${ }^{\circ} \mathrm{C}$ \\
\hline u & wind speed above crop & $\mathrm{m} \mathrm{s}^{-1}$ \\
\hline $\mathrm{u}_{\mathrm{z}, \mathrm{ws}}$ & wind speed measured at weather station & $\mathrm{m} \mathrm{s}^{-1}$ \\
\hline $\mathrm{u}_{*}$ & friction velocity & $\mathrm{m} \mathrm{s}^{-1}$ \\
\hline $\mathrm{X}_{\mathrm{f}, \mathrm{crop}}$ & horizontal extent of crop surface & $\mathrm{m}$ \\
\hline $\mathrm{X}_{\mathrm{f} \text {,region }}$ & horizontal extent of cropping in a region & $\mathrm{m}$ \\
\hline $\mathrm{x}_{\mathrm{f}, \mathrm{WS}}$ & horizontal extent of a surface under the weather station & $\mathrm{m}$ \\
\hline $\mathrm{z}_{\mathrm{h}}$ & height at which temperature is measured & $\mathrm{m}$ \\
\hline$Z_{\mathrm{IBL}, \text { crop }}$ & height of the internal boundary layer over crop & $\mathrm{m}$ \\
\hline $\mathrm{Z}_{\mathrm{IBL}, \mathrm{R}}$ & height of the internal boundary layer over region & $\mathrm{m}$ \\
\hline$Z_{\mathrm{IBL}, W S}$ & height of the internal boundary layer over weather station & $\mathrm{m}$ \\
\hline $\mathrm{z}_{\mathrm{m}}$ & height at which wind speed is measured & $\mathrm{m}$ \\
\hline $\mathrm{z}_{0 \mathrm{~m}}$ & roughness length for momentum transfer & $\mathrm{m}$ \\
\hline $\mathrm{Z}_{0 \mathrm{~m}, \mathrm{crop}}$ & roughness length for momentum transfer of crop & $\mathrm{m}$ \\
\hline $\mathrm{Z}_{0 \mathrm{~m}, \text { region }}$ & average roughness length for momentum transfer for the region & $\mathrm{m}$ \\
\hline $\mathrm{z}_{0 \mathrm{~m}, \mathrm{ws}}$ & roughness length for momentum transfer for the weather station & $\mathrm{m}$ \\
\hline $\mathrm{Z}_{\mathrm{Oh}}$ & roughness length for heat transfer & M \\
\hline$\beta_{\mathrm{m}}, \beta_{\mathrm{h}}$ & parameters used to determine in $\Psi_{m}$ and $\Psi_{n}$ in stable conditions & - \\
\hline$\Delta$ & slope of the saturated vapour pressure curve & $\mathrm{kPa}{ }^{\circ} \mathrm{C}^{-1}$ \\
\hline$\gamma$ & psychometric constant & $\mathrm{kPa}{ }^{\circ} \mathrm{C}^{-1}$ \\
\hline$\gamma^{*}$ & product of psychometric constant and $1+r c r a$ & $\mathrm{kPa}{ }^{\circ} \mathrm{C}^{-1}$ \\
\hline$Y_{m}, Y_{h}$ & parameters used to determine in $\Psi_{m}$ and $\Psi_{\mathrm{n}}$ in unstable conditions & - \\
\hline$\rho$ & Density of air & $\mathrm{kg} \mathrm{m}^{-3}$ \\
\hline$\Psi_{\mathrm{m}}$ & stability correction factor for momentum transfer & - \\
\hline$\Psi_{\mathrm{h}}$ & stability correction factor for heat and vapour transfer & - \\
\hline
\end{tabular}


In a similar manner, $\mathrm{H}$ is defined as:

$$
H=\rho c P T c-\text { Tara }
$$

In the expression for LE, the slope of the saturated vapour pressure curve, $\Delta$, given as

$$
\Delta=e c *-e a * T c-T a
$$

can be used to eliminate $e_{c}{ }^{*}$, where $e_{a}{ }^{*}$ is the saturated vapour pressure of the air, calculated from $T_{a}$ (Allen et al., 1998).

$\mathrm{G}$ is estimated in the daytime as $10 \%$ of $R_{n}$ and as $50 \%$ of $R_{n}$ during the night (Allen et al., 1998).

With substitution of [2] to [4] into [1] following Clawson et al. (1989), an expression for $T_{c}$ is:

$$
T c=T a+R n-G r a \rho c p \gamma \star \Delta+\gamma *-e a *-e a \Delta+\gamma *
$$

with

$$
\gamma *=\gamma 1+r c r a
$$

Dependent on standard meteorological variables commonly used in crop models to calculate evapotranspiration, calculation of canopy temperature is complex due to its highly nonlinear dependence on canopy (stomatal) and aerodynamic resistance terms. The latter is a function of wind speed and heat flux, while the former is a function of plant stomatal conductance which varies within a plant as a function of radiation intensity, $\mathrm{CO}_{2}$ concentration, water stress, plant nitrogen concentration and age (Leuning, 1995; Pury and Farquhar, 1997). Only detailed process-based crop models simulate photosynthesis and stomatal conductance (inverse of stomatal resistance), and these models are generally not suitable for application beyond the single field level. However, the canopy temperature upper $\left(T_{C, U}\right)$ and lower $\left(T_{C, L}\right)$ bounds (Clawson et al., 1989) can be estimated from standard weather data and the energy balance approach above by making assumptions about $r_{c}$ under two extreme states of water stress. For given climatic conditions, $T_{c, U}$ can be expressed as: 


$$
T c, U=T a+r a \rho C P
$$

and is reached when the crop does not transpire (stomatal conductance is zero, or crop resistance to water flux is infinite, $\left.r_{c}=\infty\right)$. In this case, $T_{c, U}$ can rise above air temperature due to radiant heating (Siebert et al., 2014).

When the crop has no water stress (stomatal conductance is at potential rate with a relatively small, constant resistance to water flux, $r_{c}=$ constant), $T_{C, L}$ is given by:

$$
T c, L=T a+r a \rho c P \gamma * \Delta+\gamma *-e a *-e a \Delta+\gamma *
$$

Values of $r_{c}$ under maximum transpiration, required for computation of $\mathrm{Y}^{*}$, are well reported in the literature [e.g. $r_{c}=70 \mathrm{~s} \mathrm{~m}^{-1}$ for grass, as used in Allen et al. (1998)].

With these two extreme potential values of canopy temperature, the simplification made in the SIMPLACE approach following Clawson et al. (1989) is that the actual value of $T_{c}$ lies between these two extremes as a function of the crop water stress, $K_{w s}$, and is given by:

$$
T c=T c, L+1-K W S T c, U-T c, L
$$

In SIMPLACE<Lintul5, DRUNIR, CanopyT>, $\mathrm{K}_{w s}$ is estimated as the ratio of actual transpiration to potential transpiration. Similar ratios are commonly calculated in crop models suitable for field or larger scale application.

While the simplification employed in SIMPLACE<Lintul5, DRUNIR, CanopyT> alleviates the need for detailed calculations of stomatal resistance, the calculation of aerodynamic resistance, $r_{a}$, using MOST to account for atmospheric stability requires iteration. Following MOST, when either forced or mixed convection dominates, the general expression for $r_{a}$ is:

$$
r a=1 u k 2 \ln z m-d z O m-\Psi m \ln z h-d z O h-\Psi h
$$

where $u$ is the wind speed over the crop surface, $k$ is the von Karmin constant, $z_{m}$ and $z_{h}$ are the heights at which wind speed and air temperature are measured, respectively, $d$ is the zero-displacement height (expression from Colaizzi et al., 2004 used in SIMPLACE), $z_{0 m}$ and $z_{0 h}$ are the roughness lengths for momentum and heat transfer, respectively, and $\Psi_{\mathrm{m}}$ and $\Psi_{\mathrm{h}}$ are the respective stability correction factors. The 
expressions used for $d, z_{0 m}$ and $z_{0 h}$ are functions of crop height and LAl, which are calculated daily in SIMPLACE<Lintul5, DRUNIR, CanopyT>. Appendix A provides a detailed description of the method used to estimate $\Psi_{\mathrm{m}}$ and $\Psi_{\mathrm{h}}$.

Following the approach of Kimball et al. (2015), in very unstable conditions (e.g. for $\mathrm{Ri}$ is less than -0.8 , see appendix $A)$, free convection dominates, and the corresponding equation for $r_{a}$ for a flat plate with characteristic dimension $D$ (assumed to be equivalent to the horizontal fetch of the canopy at uniform $T_{c}$ ) and parameters from Monteith and Unsworth (1990) for the Nusselt, Prandtl and Grashof numbers for under laminar conditions (Grashof number less than $10^{5}$ ), is used, such that:

$$
r a=\rho c \operatorname{PnT} T-T a 14
$$

with $\mathrm{n}$ equal to 100.0 for $\mathrm{D}$ of $3.0 \mathrm{~m}$, the plot diameter.

The interdependence of equations [4] through [11] requires iteration as no analytical solution is possible. The iterative process used in SIMPLACE $<$ Lintul5, DRUNIR, Canopy $T>$ is done twice, once for each of $T_{C, L}$ and $T_{C, U}$, as summarized in Figure 1. With the hourly estimates of $T_{C, L}$ and $T_{C, U}$, an hourly estimate of crop water stress, $K_{W s}$, is computed, and $T_{C}$ is calculated with equation (9). 


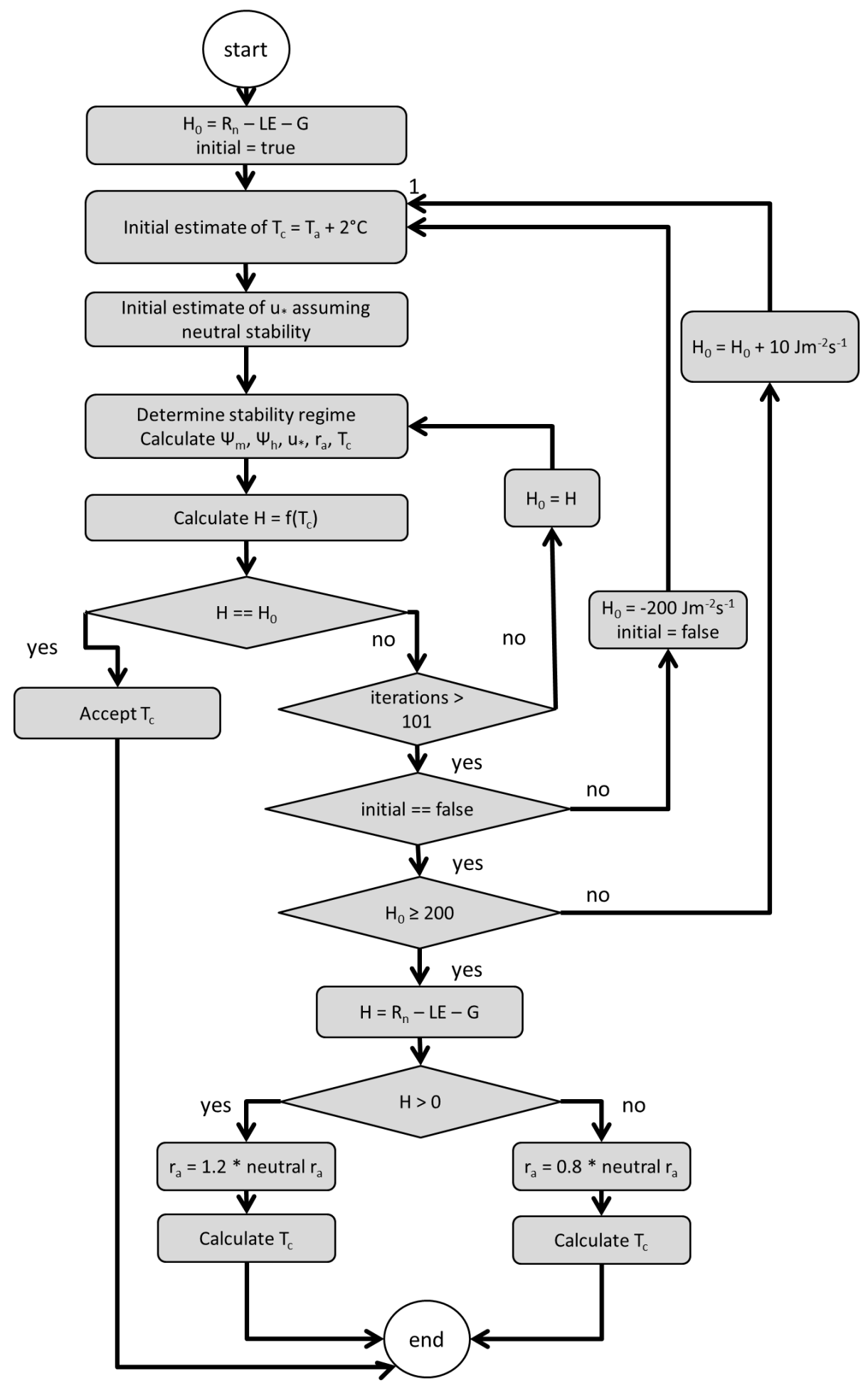

Figure 1. Flowchart illustrating the hourly canopy temperature simulation procedure for each of $T_{C, L}$ and $T_{C, U}$ used by SIMPLACE<Lintul5, DRUNIR, CanopyT>. ${ }^{1}$ Used only for highly unstable cases when $\mathrm{Ri}<0.8$ and free convection dominates. 
Daily weather values are used as inputs by SIMPLACE<Lintul5, DRUNIR, Canopy $T>$. From these daily inputs, hourly distributions of radiation and temperature are generated using algorithms of Nguyen et al. (2014) and Goudriaan and van Laar (1994), respectively. Appendix $B$ details the procedure used to convert wind speeds measured at weather stations at each site, which were situated over short grass surfaces, into wind speeds over the crop, either wheat or maize, depending on the site. Hourly calculations (Jensen et al., 1990) of potential crop transpiration were used to estimate hourly crop water demand with Penman (1948), used in Lintul-2 DRUNIR. Likewise, hourly crop water uptake was used with the hourly crop water demand to calculate hourly crop water stress, $K_{w s}$, which ranges from 0.0 with full water stress to 1.0 when crop uptake equals the ET demand.

\subsection{Description of the experimental data used in model evaluation}

The validity and general applicability of the model were evaluated using observed canopy temperatures for wheat and maize grown under two distinct climatic and management conditions. At the first location, irrigated spring wheat 'Yecora Rojo' was

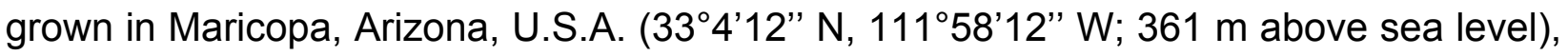
a hot and arid environment. Climate data, measured infrared canopy temperatures, soil water holding properties, emergence dates and irrigation and fertilizer management data were used from the Hot Serial Cereal (HSC) experiment conducted between 2007 and 2009. Wheat was sown every six weeks over two years (though three summer-planted crops failed to grow beyond about the 5-leaf stage), so that it grew under a wide range of temperature conditions. Additionally, infrared heaters supplied additional heating for heated plots, every other sowing date. The heaters were controlled to maintain the heated plots at target temperature increases of $1.5^{\circ} \mathrm{C}$ and $3{ }^{\circ} \mathrm{C}$ warmer than reference plots (no heat supplied by the heaters) in the day and night, respectively. Canopy temperatures were measured continuously, though only measurements taken when the crop had a full canopy cover and had not begun senescence are considered in this study. Before this period, the infrared temperature measurements were greatly influenced by the soil temperature and afterward by reduced stomatal conductance and changed albedo associated with senescence. A weather station was located near the 
center of the experimental field, which measured air temperature, solar radiation, and wind speed most of the time. Data from this station was aggregated to daily values for use as inputs to SIMPLACE. The air temperature sensor was mounted in an aspirated radiation shield at the 2-m height. When the field weather station was inoperable, regression equations were used to extrapolate data from a standard AZMET (http://ag.arizona.edu/AZMET/06.htm) weather station about $1 \mathrm{~km}$ from the experimental field. Humidity and rainfall were obtained from the AZMET station. The experiment and site details are described in Wall et al. (2011), Ottman et al. (2012), Kimball et al. (2012; 2008), and White et al. (2011b).

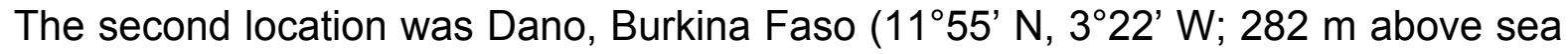
level) where rainfed maize was grown in 2013. This semi-arid location in the Sudan Savanna of West Africa experiences one rainy season per year. A 90-day variety of maize from Ghana, Bihilifa YDT, was cultivated organically, using adequate manure to minimize nutrient stress. The site was located in a valley bottom with shallow soils of 40 cm depth classified as a shallow Pisoplinthic Plinthosol (WRB 2006). The crop was sown in June in plots of $50 \mathrm{~m}^{2}$. The results presented here had no treatments imposed and represent the average canopy temperature measured at two points in a field of the size $20 \mathrm{~m}$ by $45 \mathrm{~m}$. Air temperature sensors housed in louvered, naturally ventilated, white radiation shields were adjusted so that they were always positioned at approximately the height of the highest maize leaf and recorded canopy temperature every 10 minutes. A standard weather station was located in an adjacent field less than $1 \mathrm{~km}$ from the site and measured air temperature, solar radiation, wind speed, precipitation and relative humidity. Weather data from the station was aggregated to daily values for input into SIMPLACE.

\subsection{Model evaluation}

The sensitivity of the integrated crop growth-canopy temperature model, SIMPLACE<Lintul5, DRUNIR, CanopyT> was compared to observations across the sites, representing a range of air temperature, radiation, vapour pressure, wind speed and soil water regimes. Specifically, the difference between canopy and air temperature, $\Delta_{T}=T_{C}-T_{a}$, was compared for simulated and observed values. The canopy temperature 
model was evaluated on the basis of visual evaluation, correlation coefficient and root mean squared error (RMSE) of the one-to-one plot of simulated versus observed $\Delta_{\mathrm{T}}$. Simple linear regressions of $\Delta_{T}$ against midday radiation, air temperature and water stress were performed to assess which controlling variable explained the deviation of $T_{c}$ from $T_{a}$. The statistical significance of the slope and the value of the slopes between the simulated and observed datasets were examined as a means of assessing if the model and observation responded in a similar manner to each other, and also between the location, sowing date and heater treatments. In a final step, cumulative thermal times (TT) above threshold temperatures ( $\left.T_{\text {threshold }}\right)$ were calculated for each treatment during the periods when the crop had a full ground cover and was actively transpiring. For each treatment, thermal times ( $\mathrm{TT}_{\text {air, }}, \mathrm{TT}_{\mathrm{C}_{-} \text {sim }}, \mathrm{TT}_{\mathrm{C}_{-} \text {obs }}$ ) were calculated hourly with (1) air, (2) simulated canopy ( $\left.\mathrm{T}_{\mathrm{C}_{-} \text {sim }}\right)$ and (3) observed canopy ( $\left.\mathrm{T}_{\mathrm{C}_{-} \text {obs }}\right)$ temperatures, respectively and $T_{\text {threshold }}$ using Equation (12) for $\mathrm{i}=$ air, C_sim and C_obs.

$$
\text { TTi=MAXTi-Tthreshold;0 }
$$

$\mathrm{TT}_{\mathrm{i}}$ were calculated for each treatment for three values of $\mathrm{T}_{\text {threshold }}\left(23^{\circ} \mathrm{C}, 25^{\circ} \mathrm{C}, 27^{\circ} \mathrm{C}\right)$, with the later acknowledged in some sources as the upper temperature limit to avoid decreases in wheat grain numbers (Ferris et al., 1998). The summation period roughly corresponds to the time just before anthesis until well into grain filling, though this varied between sowing date treatments due to the fact that the March sowing dates did not have as many observed canopy temperature records. For each of the three $T_{\text {threshold }}$ values, $\mathrm{TT}_{\text {air }}$ and $\mathrm{TT}_{\mathrm{C}_{-} \text {sim }}$ were regressed against $\mathrm{TT}_{\mathrm{C}_{-} \text {obs }}$ and evaluated on the basis of their slope. Statistically significant slopes, with a value close to one would indicate very good agreement with the thermal time determined using observed canopy temperature.

\section{Results}

\subsection{Agreement between simulated and observed canopy-air temperature differences}

The time course of daily maximum $T_{a}$, together with simulated and observed values of $T_{C}$ are presented in Fig. 2. Observations of $\Delta_{T}$ were generally well simulated by SIMPLACE<Lintul5, DRUNIR, CanopyT> for wheat with the Arizona HSC experiment, 
with the exception of the January 2008 sowing date (Fig. 3) and a bias towards underestimation for the March 2007 sowing date. Kimball et al. (2015) report the same problem with simulation of Tc for the January 2008 sowing date. $\Delta_{T}$ was relatively well reproduced for maize in the Burkina Faso experiment (Fig. 4). Though the correlation is weaker for this experiment, this was expected as during the rainy season, the degree of cloudiness can vary greatly between days limiting the validity of the assumption that daily radiation followed a sinusoidal distribution.
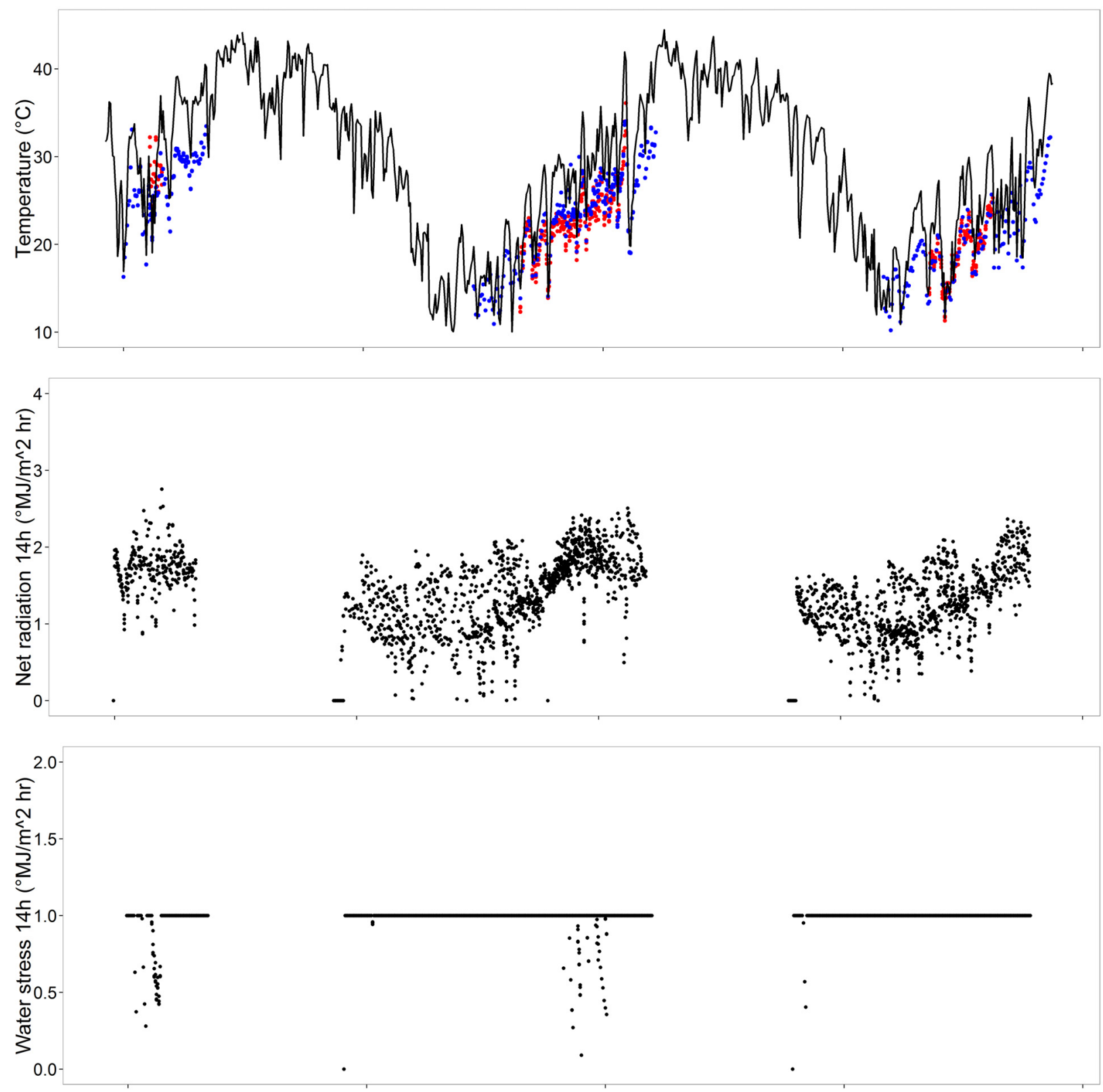
Figure 2. The top panel shows the daily maximum air temperature (black line) over the course of the HSC experiment with observed (red closed circles) and simulated (blue closed circles) canopy temperatures for the non-heated plots. The middle panel shows the simulated net radiation ( $\mathrm{MJ} \mathrm{m}^{-2} \mathrm{hr}^{-1}$ ) at the crop canopy at $14.00 \mathrm{~h}$ and the bottom panel shows the simulated hourly water stress $\left(\mathrm{K}_{\mathrm{ws}}\right)$ at $14.00 \mathrm{~h}$. 
(a) Mar 2007 sowing

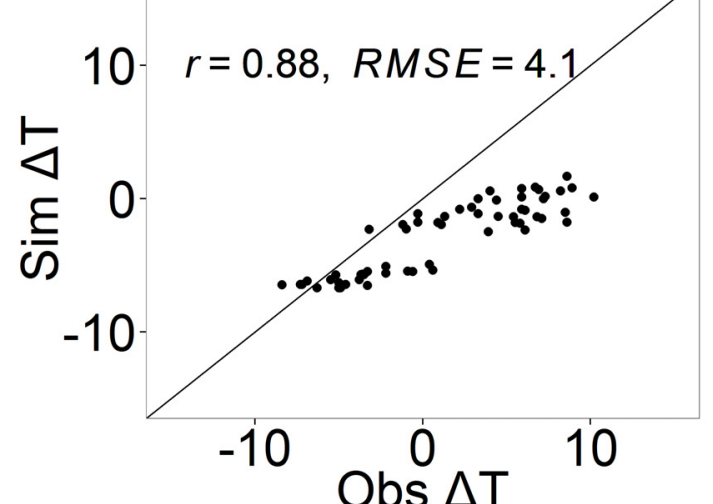

(c) Jan 2008 sowing

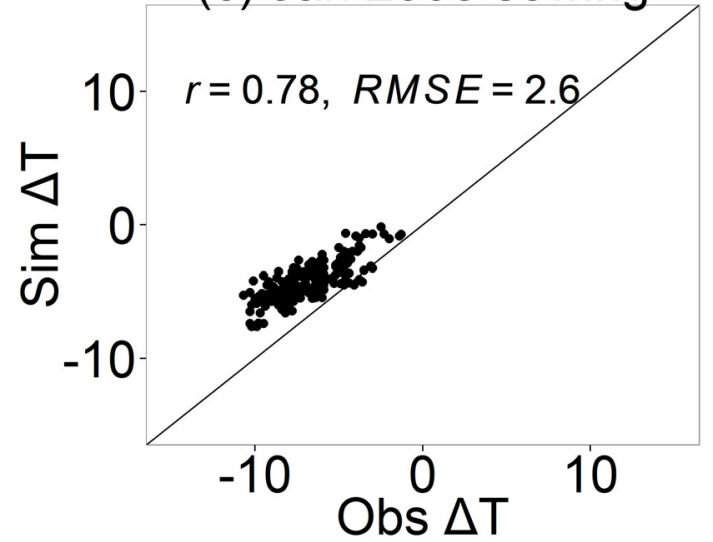

(e) Sep 2008 sowing

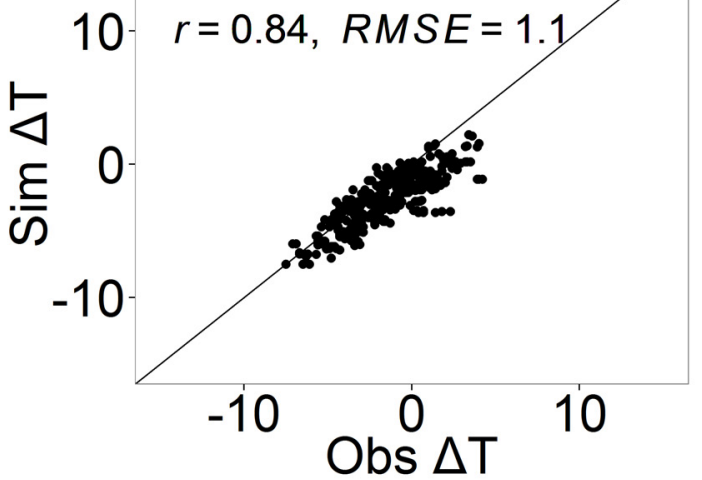

(b) Sep 2007 sowing

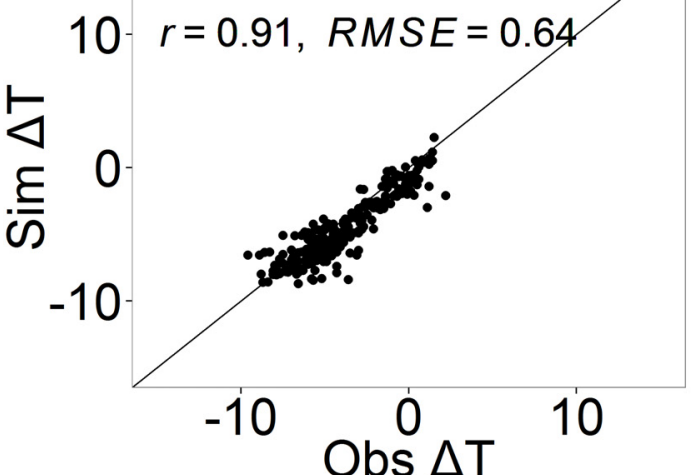

(d) Mar 2008 sowing

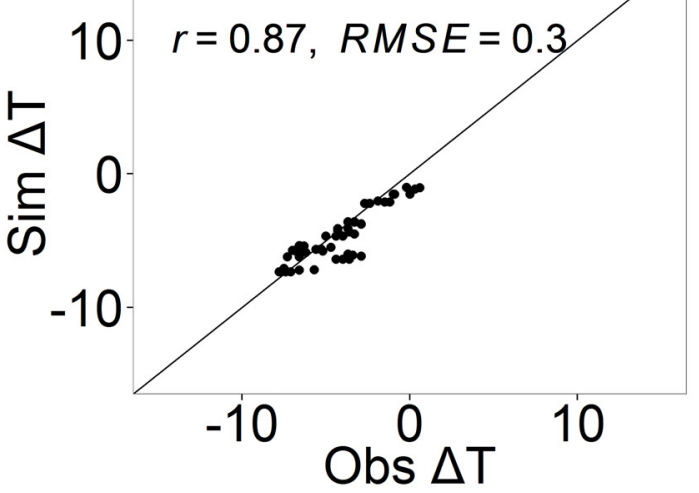

(f) Dec 2008 sowing

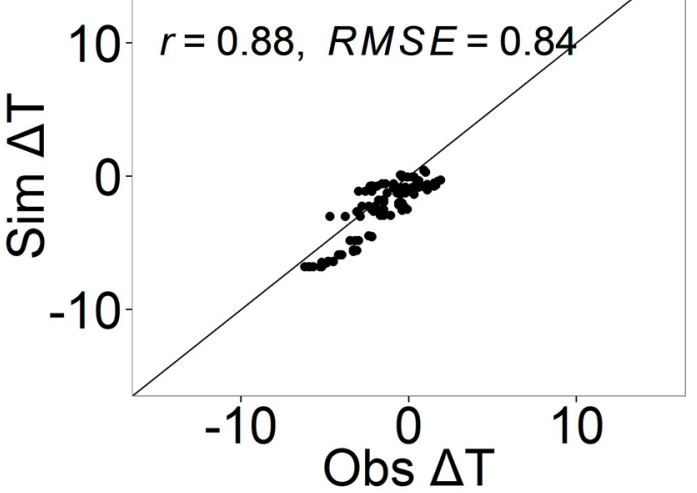

Figure 3. Observed versus simulated values of the difference between canopy and air temperature, $\Delta_{T}=T_{c}-T_{a}$, at 14.00h for the HSC experiment for (a) March 2007, (b) September 2007, (c) January 2008, (d) March 2008, (e) September 2008, and (f) December 2008 sowing dates. Each panel includes control and heated treatments. The grey line is the 1:1 line for visualization of goodness-of-fit 


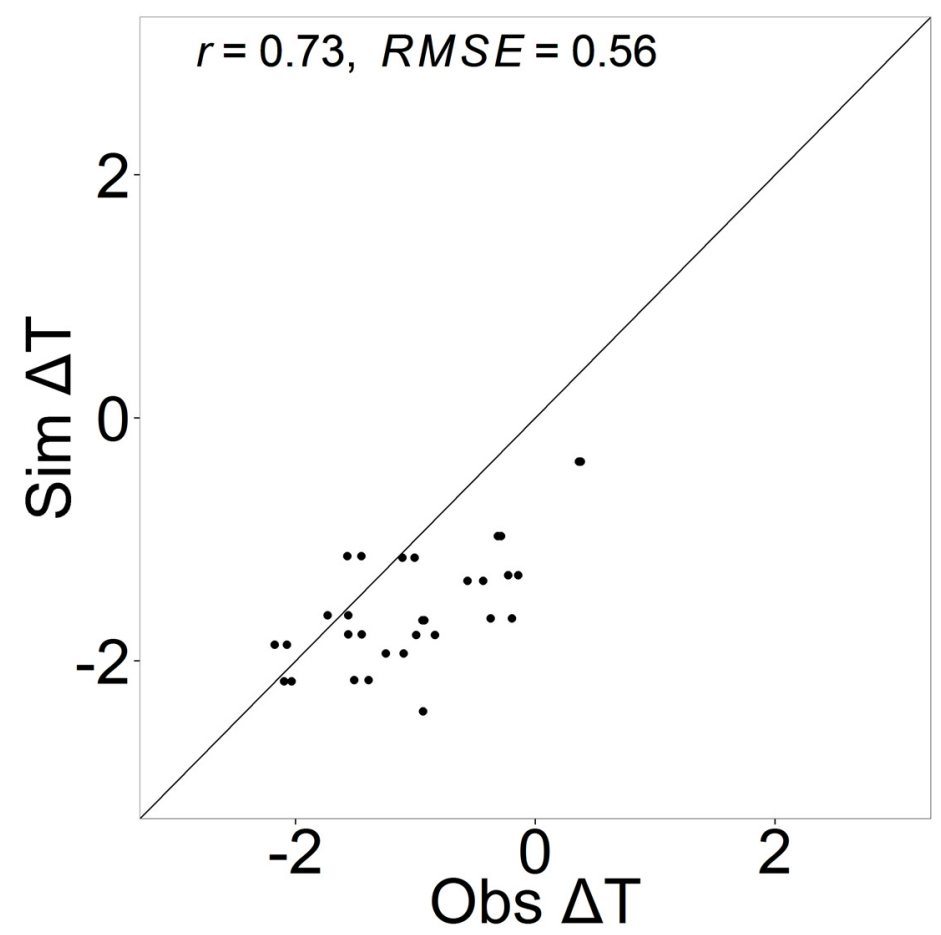

Figure 4. Observed versus simulated values of the difference between canopy and air temperature, $\Delta_{T}=T_{C}-T_{a}$, at $14.00 \mathrm{~h}$ for maize sown in the rainy season at Dano, Burkina Faso. The grey line is the 1:1 line for visualization of goodness-of-fit.

\subsection{Response of canopy-air temperature difference to climate drivers}

Averaged across all sowing dates and heating treatments for the irrigated wheat dataset, the difference between $\Delta_{T}$ became more negative as daily maximum air temperature increased (Fig. 5a). This relationship existed for both the observed and simulated $\Delta_{T}$ though with more scatter in the observations. As expected, $\Delta_{T}$ became more positive with water stress (Fig. 5c), with agreement between the observations and modelling results. However, the relationship of an increasing $\Delta_{T}$ as net radiation increased present in the observations was not reproduced as strongly in the simulations (Fig. 5b). Examination of this figure suggests that there were at least two relationships present corresponding to different environments. To investigate this effect, the relationship between $\Delta_{T}$ and net radiation was plotted separately for the four sowing dates and heating treatment combinations (Fig. 6). The simulated and observed slopes are largely similar suggesting the model correctly captured the main climate drivers of 
the difference between canopy and air temperature. Likewise, the intercepts are generally very similar for the 2008 sowing dates, with more variation between the intercepts of the simulated and observed regression relationships in 2007. However, the slope of the observed $\Delta_{T}$ versus radiation varies widely between sowing dates, years and heated treatments. This is particularly evident for the spring sowing dates, in which the observed slope, in all cases significant, varies by a factor of four.

(a) Air temperature at $14 \mathrm{~h}$

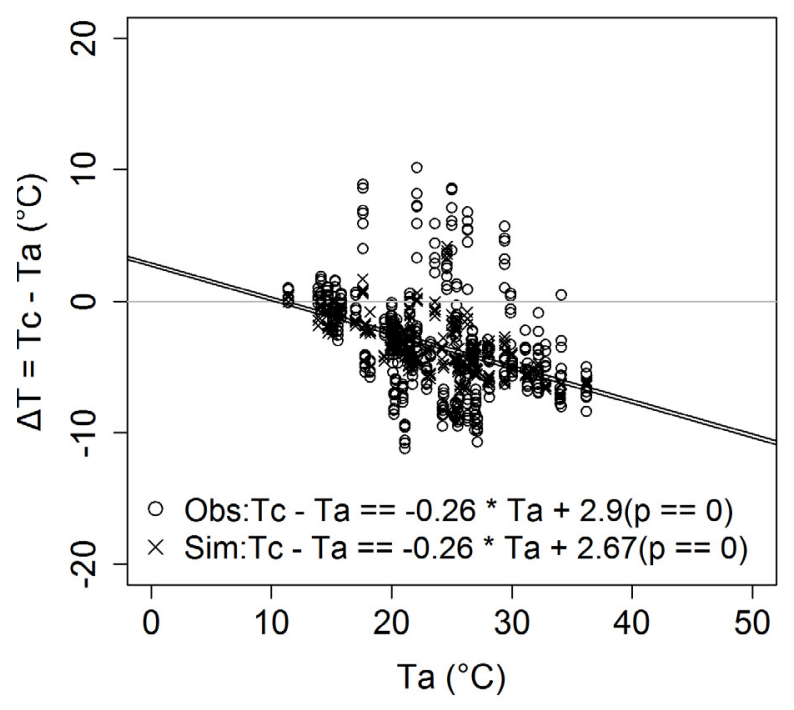

(c) Water stress at $14 \mathrm{~h}$

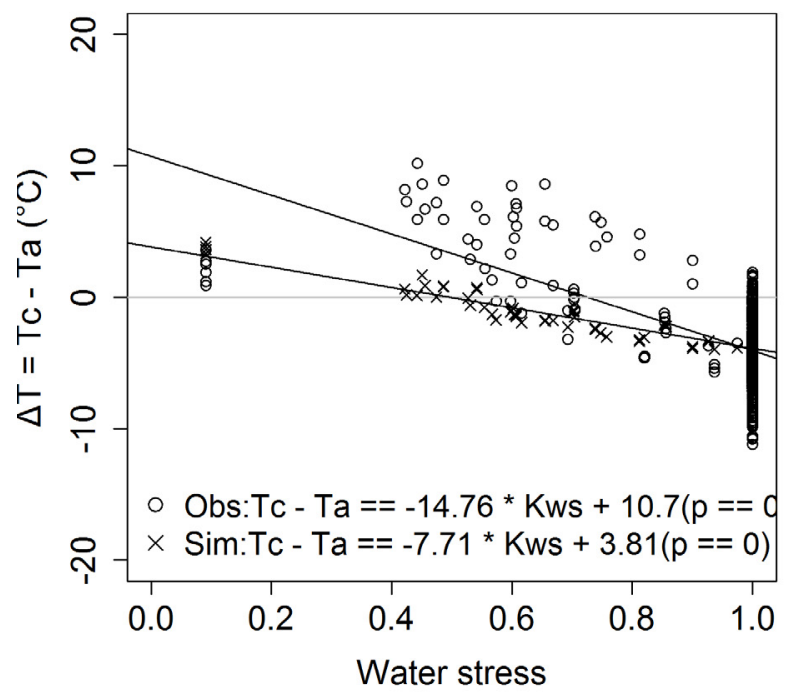

(b) Radiation at $14 \mathrm{~h}$

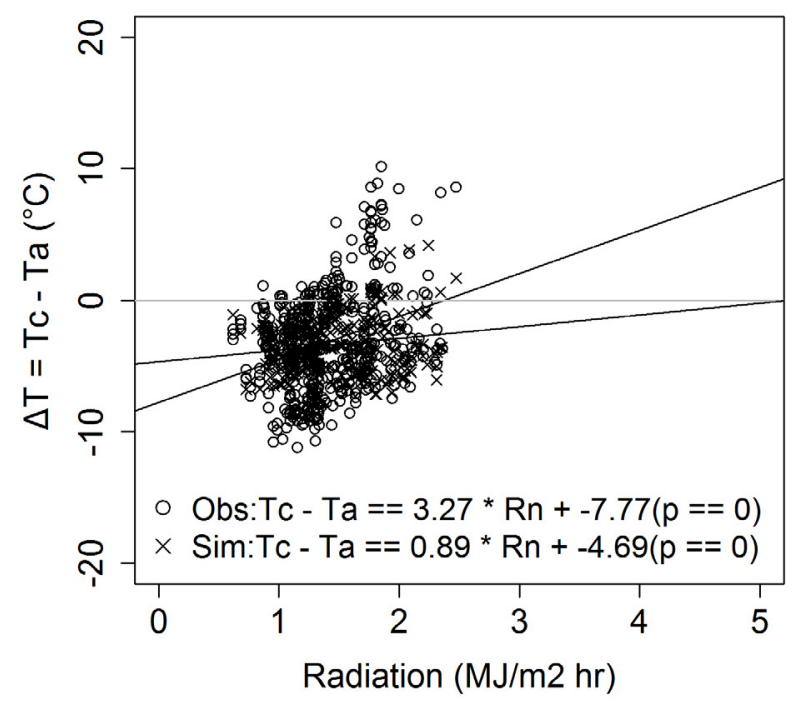


Figure 5. Regressions of observed (open circles) and simulated (crosses) values of the difference between canopy and air temperature, $\Delta_{T}=T_{c}-T_{a}$, versus (a) air temperature $\left(T_{a}\right)$, (b) net radiation $\left(R_{n}\right)$ at $14.00 \mathrm{~h}$, and (c) water stress $\left(K_{w s}\right)$ all at $14.00 \mathrm{~h}$ for the HSC experiment for the control and heated plots and March 2007, January 2008, March 2008 and December 2008 sowing dates. $p$ values indicate the statistical significance of the slopes. Note that water stress values of 1.0 denote no water stress and values of 0.0 denote the greater level of water stress.

(a) Mar 2007 sowing control

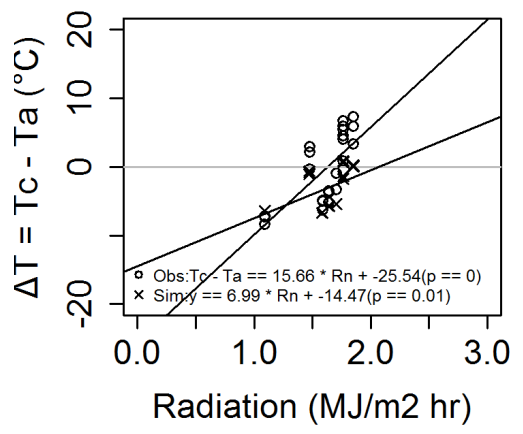

(d) Jan 2008 sowing heated

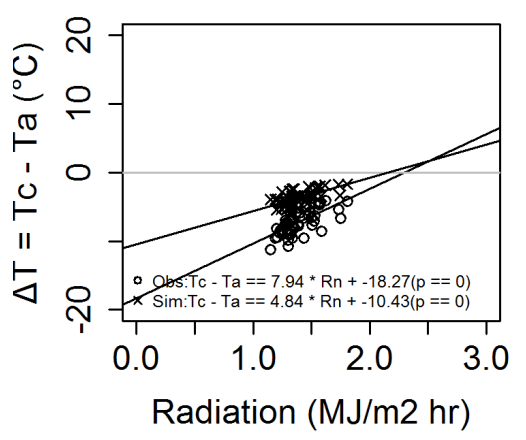

(g) Dec 2008 sowing control

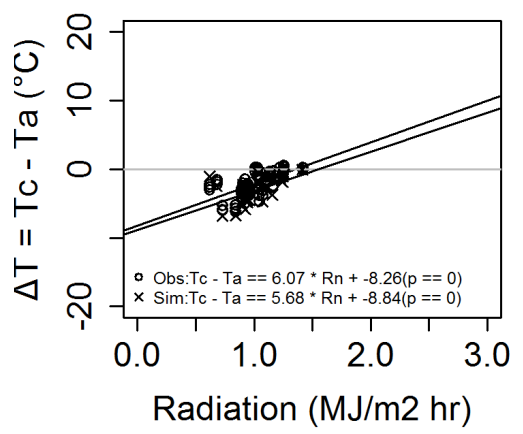

(b) Mar 2007 sowing heated

(c) Jan 2008 sowing control

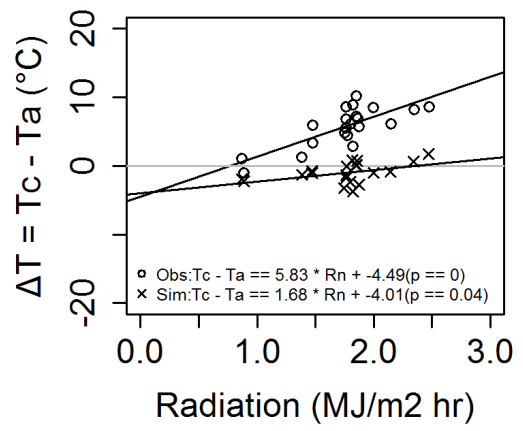

(e) Mar 2008 sowing control

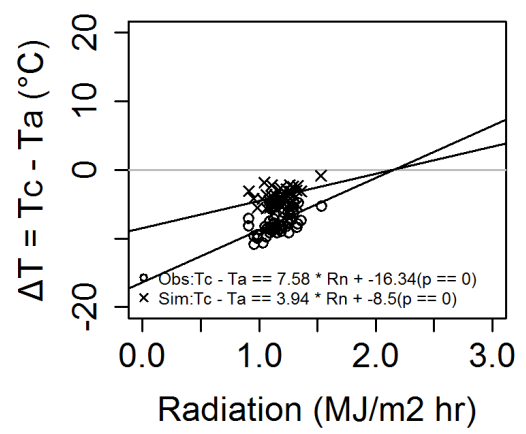

(f) Mar 2008 sowing heated
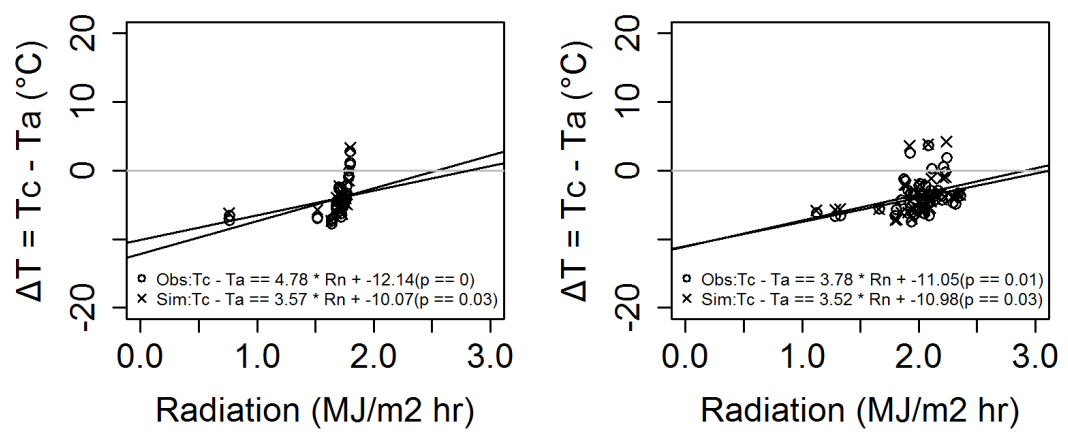

(h) Dec 2008 sowing heated

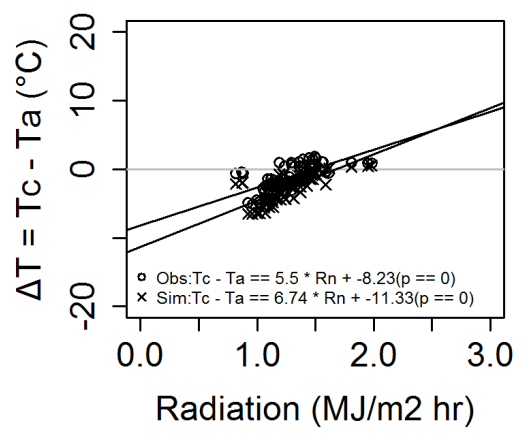


Figure 6. Regressions of observed (open circles) versus simulated (crosses) values of the difference between canopy and air temperature, $\Delta_{T}=T_{c}-T_{a}$, at $14.00 \mathrm{~h}$ versus net radiation $\left(R_{n}\right)$ at $14.00 \mathrm{~h}$ for the HSC experiment for (a) March 2007 control, (b) March 2007 heated, (c) January 2008 control, (d) January 2008 heated, (e) March 2008 control, (f) March 2008 heated, (g) December 2008 control and (h) December 2008 heated sowing date-heater treatment combinations. $p$ values indicate the statistical significance of the slopes

For rainfed maize in the Burkina Faso experiment, $\Delta_{T}$ decreased as ambient air temperature increased, and there was good agreement between the observed and simulated $\Delta_{T}$ (Fig. 7a). Both the modelled and observed $\Delta_{T}$ indicate a trend to decreasing slightly with increasing levels of midday radiation (Fig. 7b), despite the fact that the distribution of radiation can deviate substantially from the sinusoidal relationship implemented in SIMPLACE<Lintul5, DRUNIR, CanopyT> on rainy days. This response, though only weakly statistically significant, is the opposite of that observed for the irrigated wheat in Arizona, where across treatments, $\Delta_{T}$ increased with increasing midday radiation. No conclusions can be drawn about the response of $\Delta_{T}$ to water stress at this site, as the experiment was conducted during the rainy season and relatively little water stress was experienced during the time when canopy temperature observations were available (Fig. 7c). 
(a) Air temperature at $14 \mathrm{~h}$

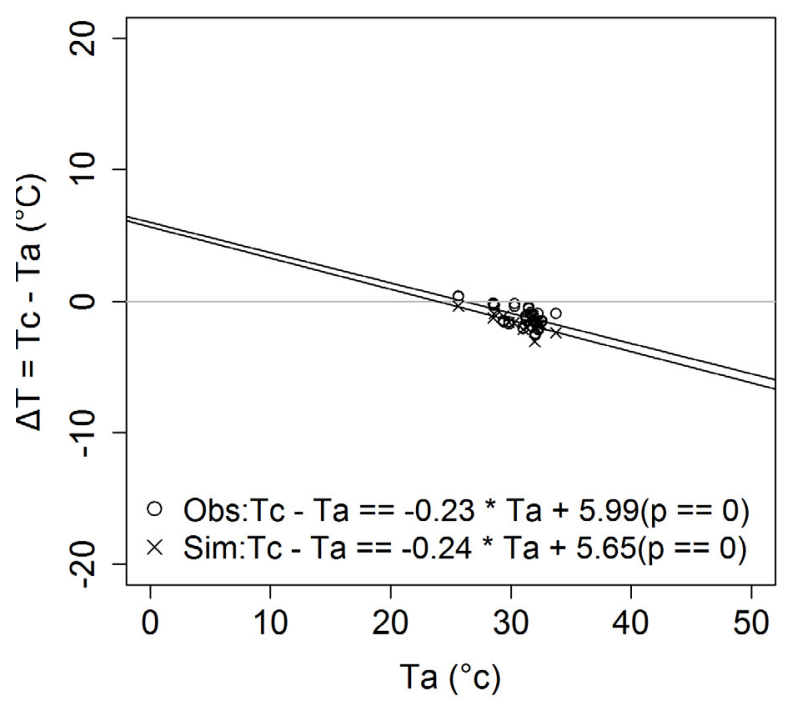

(c) Water stress at $14 \mathrm{~h}$

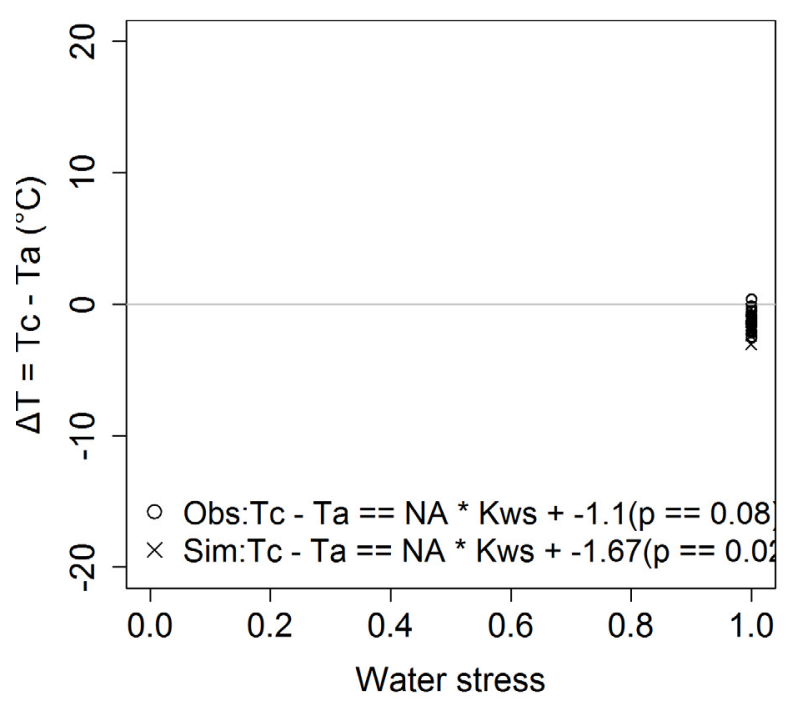

(b) Radiation at $14 \mathrm{~h}$

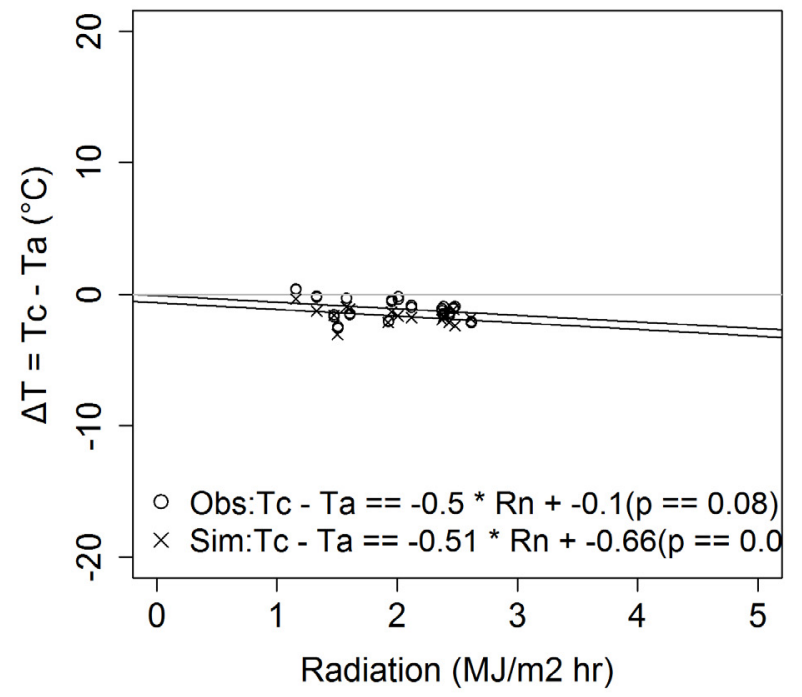

Figure 7. Regressions of observed (open circles) and simulated (crosses) values of the difference between canopy and air temperature, $\Delta_{T}=T_{c}-T_{a}$, versus (a) air temperature $\left(T_{a}\right)$, (b) net radiation $\left(R_{n}\right)$, and (c) water stress, all at $14.00 \mathrm{~h}$ for rainfed maize at the Dano, Burkina Faso site. $p$ values indicate the statistical significance of the slopes

\subsection{Heat stress intensity}


Thermal time calculated with simulated canopy temperature was able to reproduce thermal time determined with the observed canopy temperatures very well when threshold temperatures of $23^{\circ} \mathrm{C}$ and $25^{\circ} \mathrm{C}$ were used, as indicated by the highly statistically significant slopes on the regressions and values close to 1 (Fig. 8). When $27^{\circ} \mathrm{C}$ was used as the threshold temperature, thermal time was overestimated with the simulated values, though the relationship between the thermal times calculated with simulated and observed $T_{c}$ was still highly significant. On the other hand, the use of air temperature in all cases lead to overestimation of thermal time, and at $27^{\circ} \mathrm{C}$, there was no relationship between thermal time estimated with air temperature and those determined using observed canopy temperatures. A similar analysis of the HSC data by Kimball et al. (2012) compared full-season growing-degree-days (not hours; GDD) with a $0^{\circ} \mathrm{C}$ threshold and found that the patterns of crop development from emergence to maturity were the same for the heated and control wheat plots when the GDD were based on canopy temperatures but not on air temperatures.

(a) Threshold $23^{\circ} \mathrm{C}$

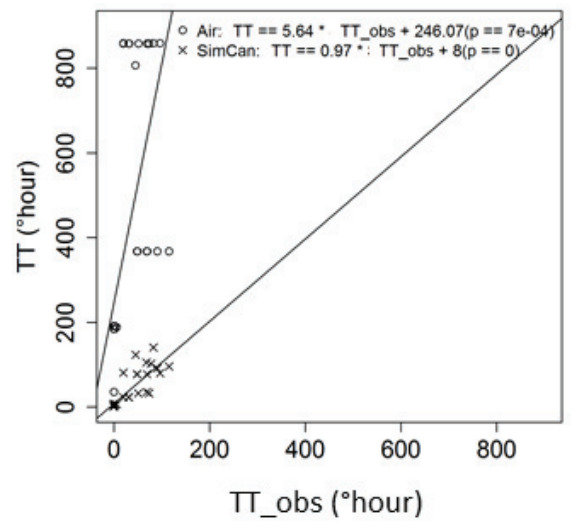

(c) Threshold $27^{\circ} \mathrm{C}$

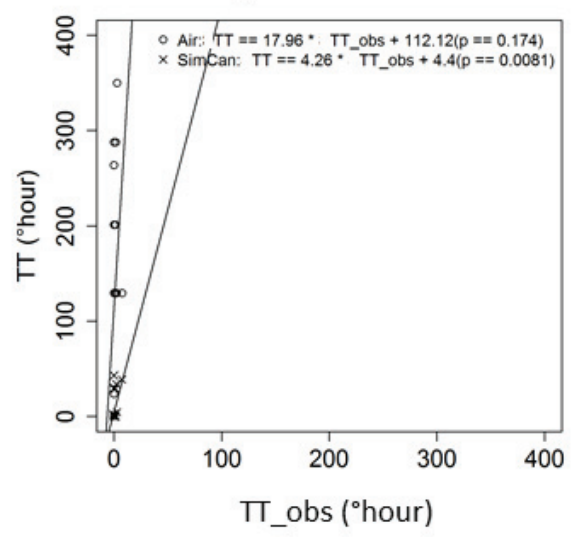

(b) Threshold $25^{\circ} \mathrm{C}$

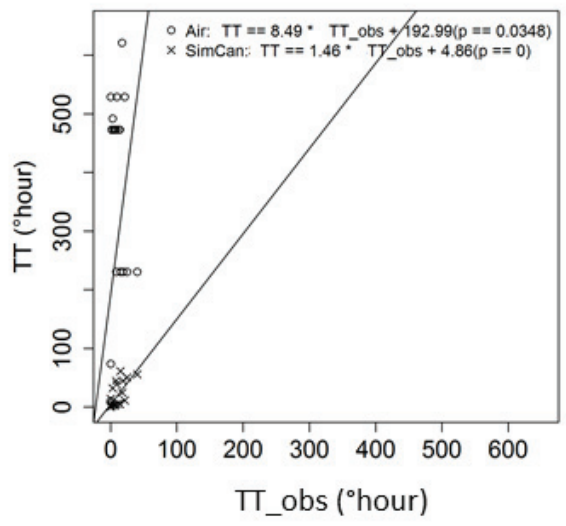


Figure 8. Regressions of thermal time (TT) $\left({ }^{\circ}\right.$ hour) estimated using (1) air temperature at $2.0 \mathrm{~m}$ height (open circles) and (2) simulated canopy temperature (crosses) versus TT estimated using observed canopy temperature (TT_obs) for the six sowing date-heater treatment combinations of the HSC experiment in Arizona, for three threshold temperatures (a) $23^{\circ} \mathrm{C}$, (b) $25^{\circ} \mathrm{C}$ and (c) $27^{\circ} \mathrm{C}$. The $\mathrm{p}$ values indicate the statistical significance of the slopes.

\section{Discussion}

As recently demonstrated by the analysis of Siebert et al. (2014), consideration of canopy temperature is important to explain the large yield losses associated to short periods of high temperature, or heat stress. The deviation between air temperature measured at two metres height and canopy temperature experienced by the crop varies with the ambient temperature, net radiation and the degree of water stress, which is itself influenced by vapour pressure deficit, soil water availability and net radiation, among other climate variables as demonstrated in Figures 4 through 6 . The first issue we examined in this study was whether simple empirical relationships could be derived between $\Delta_{T}$ and key climate drivers.

The data presented in Figure 5 exhibit considerable scatter that arises as the irrigated wheat crop $\Delta_{T}$ are aggregated across heating and sowing dates. It is only when the sowing dates and heated treatments are separated that strong empirical relationships emerge (Fig. 6). In this case, the differences between the slope and intercepts of the observed $\Delta_{T}$ when regressed against net radiation suggests that establishing robust empirical relationship is difficult even for the same crop grown with the same management at the same location, though at different times of the year. This lack of empirical relationships to explain $\Delta_{T}$ is again evident when the results for irrigated wheat in Arizona and rainfed maize in Burkina Faso are compared. In this case, different responses to increasing radiation, as indicated by the different slopes. Collectively, these results suggest that simple empirical relationships based on single variable linear regressions to describe the difference between $T_{c}$ and $T_{a}$ cannot indicate, across 
locations, management regimes or varying climatic conditions at the same location, the cause of the difference between $T_{c}$ and $T_{a}$. Multivariate, non-linear relationships may be more suitable to reveal patterns between the difference between canopy and air temperature and the main driving variables.

Our process-based model was able to reproduce the observed canopy-air temperature data well across locations and crops (Fig. 3 and 4). Further, it was able to reproduce thermal times, which are commonly used to control a range of crop development and growth processes in crop models (Fig. 8). For the three thermal times calculations evaluated in this study with threshold temperatures nearing those found to reduce wheat grain number (Ferris et al., 1998; Wheeler et al., 2000), those calculated with $T_{a}$ led to large overestimates of thermal time for the irrigated dataset. With a threshold of $27^{\circ} \mathrm{C}$, commonly used as the air high temperature threshold for heat stress impacts on wheat grains (Rezaei et al., 2015), there was no relationship between thermal time computed with $T_{a}$ and that calculated with the observed $T_{c}$. The actual high temperature threshold for grain number reduction is $31{ }^{\circ} \mathrm{C}$ (Porter and Gawith, 1999; Wheeler et al., 2000), but irrigation in the HSC experiment precluded testing the thermal times with this threshold due to a lack of observed $T_{c}$ in this range. An important implication of this finding is that $T_{a}$ would not be useful in simulating heat stress for conditions similar to those in the irrigated wheat experiment and this is expected it to also hold for rainfed crop production where $T_{c}$ can rise above $T_{a}$ (Clawson et al., 1989; Siebert et al., 2014).

However, simulating canopy temperature using the MOST approach is not without problems. The method requires considerable computational steps as it operates on an hourly basis and must iterate to find solutions. In the two crop-environment combinations investigated here, the model failed to converge in approximately $10 \%$ of the cases, roughly the same for each environment, and we have not yet been able to implement a solution that ensures greater convergence. When the model does not converge, $r_{a}$ is estimated as $20 \%$ less than and greater than $r_{a}$ for neutral stability conditions, for unstable and stable conditions, respectively, as estimated from the energy balance computed with the initial estimate of LE from DRUNIR. While, simpler empirical and semi-empirical formulations of $r_{a}$ exist (e.g. Choudhury et al., 1986; 
Shuttleworth and Gurney, 1990), our study demonstrates that the response of canopyair temperature difference can vary even for the same crop, location and management under different climatic conditions. This suggests that the suitability of more empirical approaches, even when developed for a particular region, should be assessed considering how climate may evolve in the future.

Finally, to use the model in regional scale applications, further work should investigate the sensitivity of the model to variables expected to show high variability at these scales, such as crop height and LAI, soil water status, as well as varying degrees of cloud cover. The approach presented here assumes a sinusoidal distribution of hourly temperatures and radiation, which is not valid in areas with variable cloudiness. While the performance of the model in Burkina Faso during the rainy season was satisfactory, this implications of this assumption needs to be tested across different environments. Additional uncertainty is introduced into the model with assumptions needed to convert windspeeds measured above a reference crop to windspeed representative of that experienced above the crop in question. The sensitivity of the translation method of Allen and Wright (1997) to estimates of $h_{\text {crop, } R}$, is significant and increases as $h_{c r o p, R}$ increases to values typical for maize and sorghum. However, the error introduced is only important for low wind speeds at which point free convection becomes more important to explain sensible heat transfer and therefore is believed to introduce relatively little error.

\section{Conclusions}

This study presented a promising method to calculate canopy temperature based on the well-accepted Monin-Obukhov Similarity Theory together with simplifying assumptions about the variation of canopy temperature with water stress. Estimates of upper and lower limits of canopy temperature, representing when a crop is not transpiring at all and fully transpiring, respectively, and interpolating between these extreme values as a function of crop water stress eliminate the need to estimate leaf level stomatal resistance. This simplification renders the method suitable for use in crop models such as SIMPLACE<Lintul5, DRUNIR, CanopyT> applied at the field and larger scales as required for climate impact assessment studies. The model was evaluated positively for two different cropping systems, i.e. irrigated wheat in Arizona and for 
rainfed maize in Burkina Faso offering a first confirmation of its more general applicability. Further testing needs to be conducted for other environments to determine the uncertainty associated with other climates, soil and plant characteristics. Further, thermal times determined with simulated canopy temperatures were able to reproduce thermal times calculated with observed canopy temperatures, whereas the use of air temperature was not. This evidence supports the claim that simulation of canopy temperatures in crop models can help to improve the simulation of heat stress intensity.

While the developed model is computationally complex and requires iteration, our simple single variable regression analysis did not identify an empirical relationship that was valid across climatic conditions or sites. Further study is needed to evaluate more complex multivariable regressions, and the performance of existing empirical canopy temperature models across environments. We have demonstrated a promising method to simulate canopy temperature, a challenge to the crop modelling community will be to assess how their models, designed and calibrated with air temperature, will perform with canopy temperature and for which crop physiological processes canopy temperature should be used.

\section{Acknowledgements}

Gunther Krauss is thanked for the help and useful discussions concerning the implementation of the canopy temperature related modules. The technical assistance of Matt Conley in obtaining and analyzing the infrared thermometer data in the Hot Serial Cereal (HSC) experiment is greatly appreciated, as well as the assistance provided by Charles Blackshear, Mary Comeau, Steve Farnsworth, Justin Laughridge, Laura M. Olivieri and Dr. Zahra Troeh. The HSC experiment was supported by the Agricultural Research Service, U.S. Department of Agriculture and the University of Arizona. The experiment in Burkina Faso was supported by the research program and graduate research program of WASCAL (West African Science Service Center on Climate Change and Adapted Land Use). Abdoulaye Ouedraogo and Phillips Arnold of the Dreyer Foundation are thanked for facilitating the experiment, as are Isaac Danso, Idoure Dabirre and Dr. Sié Sylvestre Da for their assistance. HW, FE, TG and DT's contributions were funded by the Federal Ministry of Education and Research (BMBF) 
through WASCAL. FE and SS acknowledge support from the German Science Foundation (project EW 119/5-1) and FE also acknowledges support from the FACCE JPI MACSUR project (031A103B) through the German Federal Ministry of Education and Research.

\section{Code availability}

SIMPLACE<Lintul5, DRUNIR, CanopyT> is freely available at http://www.simplace.net/Joomla/index.php/download. 


\section{Appendix A: Estimation of the stability correction functions}

SIMPLACE<Lintul5, DRUNIR, CanopyT> uses the method of Thom (1975) in an attempt to solve exactly MOST for $\Psi_{\mathrm{m}}$ and $\Psi_{\mathrm{h}}$. Both $\Psi_{\mathrm{m}}$ and $\Psi_{\mathrm{h}}$ are a function of the stability regime, essentially implying instability and enhanced heat transfer when the canopy is hotter than the air, and stable conditions with reduced convective heat transfer when the canopy is colder than the air. However, as the canopy temperature is unknown, an iterative approach is used to determine the stability regime, and then canopy temperature. In SIMPLACE<Lintul5, DRUNIR, CanopyT> this is done by first estimating the Richardson number, Ri, as a function of the Monin-Obukhov length (Monteith and Unsworth, 1990), L:

$$
L=-\rho c P u * 3 T a, a b s g k H
$$

where $\mathrm{u}_{*}$ is the friction velocity, $T_{a, a b s}$ is the absolute air temperature, $\mathrm{k}$ is the von Karmin constant, $g$ is the acceleration due to gravity and $H$ is the sensible heat flux. $u_{*}$ is calculated as:

$$
u *=-k u \ln z-d z o m-\Psi_{m}
$$

$\mathrm{Ri}$ itself depends on stability, and under stable or only slightly unstable conditions, Webb (1970), as reported in Monteith and Unsworth (1990), find:

$$
R i=-z m-d L+5 z m-d
$$

In unstable conditions, according to Dyer and Hicks (1970) and Monteith and Unsworth (1990), Ri is given by:

$$
R i=-z m-d L
$$

With Ri defined, the stability correction functions, $\Psi_{\mathrm{m}}$ and $\Psi_{\mathrm{h}}$, are computed for the appropriate stability condition with the following expressions as reported in Colaizzi et al. (2004) and Liu et al. (2007). In unstable conditions:

$$
\Psi_{m \varsigma}=2 \ln 1+x 2+\ln 1+x 22-2 \tan -1 x+\pi 2
$$


and

$$
\Psi_{h \varsigma}=2 \ln 1+y 2
$$

where:

$$
\begin{gathered}
x=1-\varsigma m Z m-d L \varsigma 14, \\
y=1-\gamma h \varsigma 12, \\
\varsigma m=Z m-d L
\end{gathered}
$$

and

$$
\varsigma h=Z h-d L
$$

The dimensionless parameters $\gamma_{m}=\gamma_{h}=16$ are from Paulson (1970).

Under stable conditions, $\Psi_{\mathrm{m}}$ and $\Psi_{\mathrm{h}}$ are computed following Liu et al. (2007), as:

$$
\Psi_{m \varsigma m=-\beta m z m-d L}
$$

and

$$
\Psi h \varsigma h=-\beta h z h-d L
$$

with dimensionless parameters $\beta_{\mathrm{m}}=\beta_{\mathrm{h}}=5$ from Webb (1970) and Businger et al. (1971), as reported in Liu et al. (2007). 


\section{Appendix B: Estimation of wind speed over crop}

Wind speed observations at weather stations, $\mathrm{u}_{z, w s}$, are translated into estimates of wind speed above the canopy, $u_{z, \text { crop. }}$ Using the method in Allen and Wright (1997) based on the concept of internal boundary layers (IBL), $\mathrm{u}_{\mathrm{z}, \text { crop }}$ is given by $u z, c r o p=u z, W S \ln z I B L, W S-d W S z O M, W S \ln z I B L, c r o p-d R z O M, R \ln z c r o p-d c r o p z O M$, cro $p \ln z W S-d W S z O M, W S \ln z I B L, W S-d R z O M, R \ln z I B L, c r o p-d c r o p z O M, c r o p$

where $z_{I B L, R}, z_{I B L, W S}, z_{I B L, \text { crop }}$ are the heights of the IBLs, $d_{R}, d_{W S}, d_{c r o p}$ the zerodisplacement heights, $\mathrm{Z}_{\mathrm{OM}, \mathrm{R}}, \mathrm{Z}_{\mathrm{OM}, \mathrm{WS}}, \mathrm{Z}_{\mathrm{OM}, \mathrm{crop}}$ the surface roughness for momentum transfer, all for the region, weather station and cropped area, respectively. The height of the IBL is calculated as

$$
z I B L=d+0.33 z O M 0.125 x f 0.875
$$

with $\mathrm{x}_{\mathrm{f}}$ the horizontal extent of the surface. The horizontal extent of the weather station, $\mathrm{x}_{\mathrm{f}, \mathrm{Ws}}$, and cropped area, $\mathrm{x}_{\mathrm{f}, \text { crop }}$, can be known and were found to have minimal impact on $r_{a}$ for typical values (results not presented). All other parameters are the same as the inputs/assumptions used in the FAO-56 estimate of reference crop ET, with the exception of an estimate of the average crop height for the surrounding agricultural

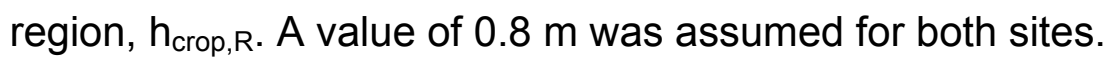




\section{References}

Allen, R.G., Pereira, L.S., Raes, D., Smith, M., 1998. Crop evapotranspiration-Guidelines for computing crop water requirements-FAO Irrigation and drainage paper 56. FAO, Rome 300 6541.

Allen, R.G., Wright, J.L., 1997. Translating wind measurements from weather stations to agricultural crops. Journal of Hydrologic Engineering 2(1) 26-35.

Angulo, C., Rötter, R., Trnka, M., Pirttioja, N., Gaiser, T., Hlavinka, P., Ewert, F., 2013.

Characteristic 'fingerprints' of crop model responses to weather input data at different spatial resolutions. European Journal of Agronomy 49 104-114.

Asseng, S., Foster, I., Turner, N.C., 2011. The impact of temperature variability on wheat yields. Global Change Biology 17(2) 997-1012.

Brisson, N., Mary, B., Ripoche, D., Jeuffroy, M.H., Ruget, F., Nicoullaud, B., Gate, P., DevienneBarret, F., Antonioletti, R., Durr, C., Richard, G., Beaudoin, N., Recous, S., Tayot, X., Plenet, D., Cellier, P., Machet, J.-M., Meynard, J.M., Delécolle, R., 1998. STICS: a generic model for the simulation of crops and their water and nitrogen balances. I. Theory and parameterization applied to wheat and corn. Agronomie 18(5-6) 311-346.

Businger, J., Wyngaard, J., Izumi, Y., Bradley, E.F., 1971. Flux-profile relationships in the atmospheric surface layer. Journal of the Atmospheric Sciences 28(2) 181-189.

Choudhury, B., Reginato, R., Idso, S., 1986. An analysis of infrared temperature observations over wheat and calculation of latent heat flux. Agricultural and Forest Meteorology 37(1) 75-88. Clawson, K., Jackson, R., Pinter, P., 1989. Evaluating plant water stress with canopy temperature differences. Agronomy Journal 81(6) 858-863.

Colaizzi, P.D., Evett, S.R., Howell, T.A., Tolk, J.A., 2004. Comparison of aerodynamic and radiometric surface temperature using precision weighing lysimeters, Optical Science and Technology, the SPIE 49th Annual Meeting. International Society for Optics and Photonics, pp. 215-229.

Craufurd, P.Q., Vadez, V., Jagadish, S.V.K., Prasad, P.V.V., Zaman-Allah, M., 2013. Crop science experiments designed to inform crop modeling. Agricultural and Forest Meteorology 170(0) 8-18.

Deryng, D., Conway, D., Ramankutty, N., Price, J., Warren, R., 2014. Global crop yield response to extreme heat stress under multiple climate change futures. Environmental Research Letters 9(3) 034011.

Durigon, A., de Jong van Lier, Q., 2013. Canopy temperature versus soil water pressure head for the prediction of crop water stress. Agricultural Water Management 127 1-6.

Dyer, A., 1974. A review of flux-profile relationships. Boundary-Layer Meteorology 7(3) 363-372.

Ewert, F., Rötter, R., Bindi, M., Webber, H., Trnka, M., Kersebaum, K., Olesen, J.E., van

Ittersum, M., Janssen, S., Rivington, M., Semenov, M., Wallach, D., Porter, J., Stewart, D., Verhagen, J., Gaiser, T., Palosuo, T., Tao, F., Nendel, C., Roggero, P., Bartošová, L., Asseng, S., in press. Crop modelling for integrated assessment of climate change risk to food production. Environmental Modelling \& Software.

Ferris, R., Ellis, R., Wheeler, T., Hadley, P., 1998. Effect of high temperature stress at anthesis on grain yield and biomass of field-grown crops of wheat. Annals of Botany 82.

Field, C.B., Barros, V., Stocker, T.F., Dahe, Q., 2012. Managing the Risks of Extreme Events and Disasters to Advance Climate Change Adaptation: Special Report of the Intergovernmental Panel on Climate Change. Cambridge University Press.

Gaiser, T., Perkons, U., Küpper, P.M., Kautz, T., Uteau-Puschmann, D., Ewert, F., Enders, A., Krauss, G., 2013. Modeling biopore effects on root growth and biomass production on soils with pronounced sub-soil clay accumulation. Ecological modelling 256 6-15. 
Goudriaan, J., Van Laar, H., 1994. Modelling potential crop growth processes: textbook with exercises. Springer.

Gourdji, S.M., Sibley, A.M., Lobell, D.B., 2013. Global crop exposure to critical high temperatures in the reproductive period: historical trends and future projections. Environmental Research Letters 8(2) 024041.

Grant, R., Baldocchi, D., Ma, S., 2012. Ecological controls on net ecosystem productivity of a seasonally dry annual grassland under current and future climates: Modelling with ecosys. Agricultural and Forest Meteorology 152 189-200.

Hatfield, J.L., Boote, K.J., Kimball, B., Ziska, L., Izaurralde, R.C., Ort, D., Thomson, A.M., Wolfe, D., 2011. Climate impacts on agriculture: implications for crop production. Agronomy Journal 103(2) 351-370.

Hawkins, E., Fricker, T.E., Challinor, A.J., Ferro, C.A., Ho, C.K., Osborne, T.M., 2013. Increasing influence of heat stress on French maize yields from the 1960s to the 2030s. Global Change Biology 19(3) 937-947.

Jamieson, P., Brooking, I., Porter, J., Wilson, D., 1995. Prediction of leaf appearance in wheat: a question of temperature. Field Crops Research 41(1) 35-44.

Jamieson, P.D., Semenov, M.A., Brooking, I.R., Francis, G.S., 1998. Sirius: a mechanistic model of wheat response to environmental variation. European Journal of Agronomy 8(3-4) 161-179.

Jensen, M.E., Burman, R.D., Allen, R.G., 1990. Evapotranspiration and irrigation water requirements. ASCE.

Kimball, B., White, J., Ottman, M., Wall, G., Bernacchi, C., Morgan, J., Smith, D., 2015.

Predicting Canopy Temperatures and Infrared Heater Energy Requirements for Warming Field Plots. Agronomy Journal 107(1) 129-141.

Kimball, B., White, J., Wall, G., Ottman, M., 2012. Infrared-Warmed and Unwarmed Wheat Vegetation Indices Coalesce Using Canopy-Temperature-Based Growing Degree Days. Agronomy Journal 104(1) 114-118.

Kimball, B.A., Conley, M.M., Wang, S., Lin, X., Luo, C., Morgan, J., Smith, D., 2008. Infrared heater arrays for warming ecosystem field plots. Global Change Biology 14(2) 309-320.

Kueppers, L.M., Snyder, M.A., Sloan, L.C., 2007. Irrigation cooling effect: Regional climate forcing by land-use change. Geophysical Research Letters 34(3) L03703.

Leuning, R., 1995. A critical appraisal of a combined stomatal-photosynthesis model for C3 plants. Plant, cell \& environment 18(4) 339-355.

Liu, S., Lu, L., Mao, D., Jia, L., 2007. Evaluating parameterizations of aerodynamic resistance to heat transfer using field measurements. Hydrology and Earth System Sciences 11(2) 769-783. Lobell, D.B., Bänziger, M., Magorokosho, C., Vivek, B., 2011. Nonlinear heat effects on African maize as evidenced by historical yield trials. Nature Climate Change 1(1) 42-45.

Lobell, D.B., Bonfils, C.J., Kueppers, L.M., Snyder, M.A., 2008. Irrigation cooling effect on temperature and heat index extremes. Geophysical Research Letters 35(9) L09705.

Lobell, D.B., Hammer, G.L., McLean, G., Messina, C., Roberts, M.J., Schlenker, W., 2013. The critical role of extreme heat for maize production in the United States. Nature Climate Change(3) 497-501.

Mihailovic, D.T., Eitzinger, J., 2007. Modelling temperatures of crop environment. Ecological modelling 202(3) 465-475.

Monin, A., Obukhov, A., 1954. Basic laws of turbulent mixing in the surface layer of the atmosphere. Contrib. Geophys. Inst. Acad. Sci. USSR 151 163-187.

Monteith, J., Unsworth, M., 1990. Principles of environmental physics., 2nd ed. Edward Arnold, London.

Moriondo, M., Giannakopoulos, C., Bindi, M., 2011. Climate change impact assessment: the role of climate extremes in crop yield simulation. Climatic Change 104(3-4) 679-701.

Nguyen, D.-N., Lee, K.-J., Kim, D.-I., Anh, N.T., Lee, B.-W., 2014. Modeling and validation of high-temperature induced spikelet sterility in rice. Field Crops Research 156(0) 293-302. 
Ottman, M., Kimball, B., White, J., Wall, G., 2012. Wheat growth response to increased temperature from varied planting dates and supplemental infrared heating. Agronomy Journal 104(1) 7-16.

Paulson, C.A., 1970. The mathematical representation of wind speed and temperature profiles in the unstable atmospheric surface layer. Journal of Applied Meteorology 9(6) 857-861.

Penman, H.L., 1948. Natural evaporation from open water, bare soil and grass. Proceedings of the Royal Society of London. Series A. Mathematical and Physical Sciences 193(1032) 120-145. Porter, J., Gawith, M., 1999. Temperatures and the growth and development of wheat: a review. European Journal of Agronomy 10(1) 23-36.

Pury, D.d., Farquhar, G., 1997. Simple scaling of photosynthesis from leaves to canopies without the errors of big-leaf models. Plant, cell \& environment 20(5) 537-557.

Rattalino Edreira, J.I., Otegui, M.E., 2012. Heat stress in temperate and tropical maize hybrids: Differences in crop growth, biomass partitioning and reserves use. Field Crops Research 130(0) 87-98.

Rezaei, E.E., Webber, H., Gaiser, T., Naab, J., Ewert, F., 2015. Heat stress in cereals:

Mechanisms and modelling. European Journal of Agronomy 64 98-113.

Rötter, R.P., Carter, T.R., Olesen, J.E., Porter, J.R., 2011. Crop-climate models need an overhaul. Nature Climate Change 1(4) 175-177.

Schlenker, W., Roberts, M.J., 2009. Nonlinear temperature effects indicate severe damages to US crop yields under climate change. Proceedings of the National Academy of Sciences 106(37) 15594-15598.

Seneviratne, S., Nicholls, N., Easterling, D., Goodess, C., Kanae, S., Kossin, J., Luo, Y., Marengo, J., Mclnnes, K., Rahimi, M., 2012. Changes in climate extremes and their impacts on the natural physical environment: An overview of the IPCC SREX report, EGU General Assembly Conference Abstracts, p. 12566.

Shuttleworth, W.J., Gurney, R.J., 1990. The theoretical relationship between foliage temperature and canopy resistance in sparse crops. Quarterly Journal of the Royal Meteorological Society 116(492) 497-519.

Siebert, S., Ewert, F., Rezaei, E.E., Kage, H., Graß, R., 2014. Impact of heat stress on crop yield-on the importance of considering canopy temperature. Environmental Research Letters 9(4) 044012.

Spitters, C., Schapendonk, A., 1990. Evaluation of breeding strategies for drought tolerance in potato by means of crop growth simulation, Genetic Aspects of Plant Mineral Nutrition. Springer, pp. 151-161.

Thom, A., 1975. Momentum, mass and heat exchange of plant communities. Vegetation and the Atmosphere 157-109.

van Ittersum, M., Leffelaar, P., van Keulen, H., Kropff, M., Bastiaans, L., Goudriaan, J., 2003. On approaches and applications of the Wageningen crop models. European Journal of Agronomy 18(3) 201-234.

Van Oijen, M., Leffelaar, P.A., 2008. Chapter 10(B) LINTUL-2: water limited crop growth. A simple crop growth model for water-limited growing conditions, Crop ecology 2008. Wageningen University: Wageningen.

van Oort, P.A.J., Saito, K., Zwart, S.J., Shrestha, S., 2014. A simple model for simulating heat induced sterility in rice as a function of flowering time and transpirational cooling. Field Crops Research 156(0) 303-312.

Wall, G.W., Kimball, B.A., White, J.W., Ottman, M.J., 2011. Gas exchange and water relations of spring wheat under full-season infrared warming. Global Change Biology 17(6) 2113-2133.

Webb, E.K., 1970. Profile relationships: The log-linear range, and extension to strong stability. Quarterly Journal of the Royal Meteorological Society 96(407) 67-90. 
Wheeler, T.R., Craufurd, P.Q., Ellis, R.H., Porter, J.R., Vara Prasad, P., 2000. Temperature variability and the yield of annual crops. Agriculture, Ecosystems \& Environment 82(1) 159-167. White, J.W., Hoogenboom, G., Kimball, B.A., Wall, G.W., 2011a. Methodologies for simulating impacts of climate change on crop production. Field Crops Research 124(3) 357-368.

White, J.W., Kimball, B.A., Wall, G.W., Ottman, M.J., Hunt, L., 2011b. Responses of time of anthesis and maturity to sowing dates and infrared warming in spring wheat. Field Crops Research 124(2) 213-222.

Wolf, J., 2012. LINTUL5: Simple generic model for simulation of crop growth under potential, water limited and nitrogen, phosphorus and potassium limited conditions. Plant Production Systems Group, Wageningen University: Wageningen.

WRB, 2006. World reference base for soil resources 2006. World Soil Resources Reports No. 103. FAO, Rome.

Zhao, G., Siebert, S., Enders, A., Rezaei, E.E., Yan, C., Ewert, F., 2015. Demand for multi-scale weather data for regional crop modelling. Agricultural and Forest Meteorology 200 156-171. 